\title{
The Value Contribution of Manufacturing Technology Suppliers
}

\author{
Thomas V. Scannell ${ }^{1}$, Kenneth J. Petersen ${ }^{2} \&$ Sime Curkovic $^{1}$ \\ ${ }^{1}$ Haworth College of Business, Western Michigan University, Kalamazoo, Michigan \\ ${ }^{2}$ Marketing and Supply Chain Management, University of Tennessee, Knoxville, Tennessee \\ Correspondence: Thomas V. Scannell, Haworth College of Business, Western Michigan University, Kalamazoo, \\ Michigan, USA. Tel: 1-269-387-5860. E-mail: thomas.scannell@wmich.edu
}

Received: August 9, 2013

Accepted: August 26, 2013

Online Published: August 27, 2013

doi:10.5430/jbar.v2n2p39

URL: http://dx.doi.org/10.5430/jbar.v2n2p39

\begin{abstract}
This research examined the value of advanced manufacturing technology (AMT) supplier support by testing a structural model that relates need for support with actual support received, and the impact of that support on implementation, operational and business success. Current research is expanded by simultaneously testing the relationship between these factors in a single model. The recent adoption of a specific subset of AMT was the unit of analysis. The proposed model has good statistical fit and the four hypotheses were supported. Firms adopting new manufacturing technologies benefit from collaborative relationships with manufacturing technology suppliers, suggesting that the service capabilities of technology suppliers be critically evaluated during supplier and AMT selection.
\end{abstract}

Keywords: Advanced manufacturing technology adoption, Supplier support, Structural equation modeling

\section{Introduction}

Companies use AMT to achieve higher performance on multiple competitive dimensions and to drive business outcomes (Zhang et al., 2006). However, some AMT adoption processes fail to deliver the planned benefits (Baldwin and Lin, 2002; Percival, 2009). Challenges include technical, human and process capability misalignment, infrastructural problems and integration failings for example (Small and Yasin, 1997; Gouveia da Costa and Pinheiro de Lima, 2009).

A company adopting AMT may secure AMT supplier support to overcome such challenges (Stock and Tatikonda, 2000; Abd Rahman and Bennett, 2009; Scannell et al., 2011). Buyer/supplier cooperation to achieve successful implementation is important not only to control costs and mitigate adoption problems, but because installation success may also impact technology performance (Efstathiades et al., 2002; Small, 2007). Despite the challenges of adopting AMT and the potential importance of collaborative AMT supplier and buyer relationships, current research into the importance of such relationships for the purchase and installation of AMT is somewhat limited (Abd Rahman and Bennett, 2009; Abd Rahman et al., 2009).

AMT refers to a range of computer controlled technologies and organizational processes used to develop and produce a product (Lewis and Boyer, 2002; Small, 2007). This research focuses on a subset of AMT: computerized numerical control (CNC) machines, direct numerical control (DNC) machines, material working lasers, and robots. This AMT subset is referred to as Shop Floor Manufacturing Technologies (SFMT) for this research. Focusing on SFMT mitigates the moderating impact of technology type (King and He, 2006; Hsiao and Yang, 2011).

A Supplier Support Technology Adoption Model was developed and tested to determine the value of AMT supplier support. Results indicate that supplier support facilitates successful technology adoption. Further, technology implementation success is associated with eventual operational success which in turn is positively associated with business performance success. These results suggest that companies should critically evaluate the need for supplier support prior to selecting an AMT. The following section reviews the literature to develop the research model and hypotheses. The research methodology is then discussed, followed by a presentation of the results. The discussion section presents managerial implications, limitations of the research, and future research directions.

\section{Review of the literature and model development}

AMT includes a variety of computer-based systems and organizational practices that are used in the development and production of a product (Lewis and Boyer, 2002; Small, 2007). AMT has been categorized by function: stand-alone 
systems such as computer aided design (CAD); intermediate systems such as computer numerically controlled (CNC) machines; and integrated systems such as enterprise resource planning (ERP) (Small and Chen, 1995). Other researchers have classified AMTs using somewhat different technology categories: design technologies such as CAD; administrative technologies such as electronic data interchange (EDI); and manufacturing technologies such as CNC (Boyer et al., 1997).

This research focused on the adoption of technologies that assemble, machine and/or fabricate products: CNC/DNC, material working lasers, and robots. This subgroup of technologies is labeled Shop Floor Manufacturing Technologies (SFMT), relatively consistent with the manufacturing technologies category of AMT suggested by Boyer et al. (Boyer et al., 1997). An AMT subset was selected because context matters when exploring technology adoption (Hsiao and Yang, 2011). Potential moderating impacts of user and usage type (King and He, 2006), and technology type (Schepers and Wetzels, 2007) were mitigated by focusing on SFMT.

Firms adopting AMT may realize operational (Dangayach and Deshmukh, 2004) and long-term business success (Boyle, 2006; Monge et al., 2006). However, there are AMT implementation challenges and the benefits of AMT are not always achieved (Baldwin and Lin, 2002; Percival, 2009). Also, though AMT has improved plant and firm performance, the rate of change has not been as significant as expected (Mital and Pennathur, 2002). Integration challenges, infrastructural issues, and planning mistakes are potential causes of AMT performance challenges (Small and Yasin, 1997; Gouveia da Costa and Pinheiro de Lima, 2009).

Small (Small, 2007) identified nineteen technology planning, justification and installation activities important to AMT adoption and performance success. The most relevant factors for this research include: linking business and manufacturing strategy; matching capabilities of AMT to the benefits expected by the firm; consideration of AMT impact on suppliers; establishing multi-disciplinary teams; pre-installation training for all project participants; and ensuring the availability of multi-skilled production workers.

These factors suggest that organizational infrastructure is critical to AMT implementation and technology performance. Without an appropriate infrastructure, a company considering adoption of a new technology may need to secure supplier support to successfully adopt the technology (Stock and Tatikonda, 2000; Scannell et al., 2012). Cooperative relationships may be appropriate across the development, purchasing, start up and production stages of technology adoption and usage (Lager and Frishammar, 2010). Firms that expect and plan for supplier support are more likely to receive that support (Abd Rahman et al., 2009). Thus, the first research hypothesis was developed:

H1: The proactive consideration of the need for technology supplier support (NTS) is positively related to the level of actual technology supplier support (ATS) realized.

The preparation, transport, storage and installation efforts associated AMT adoption may constitute a large portion of the time and costs of adoption (Mital and Pennathur, 2002). Firms which develop closer equipment supplier and buyer relationships may realize higher levels of technology implementation success than firms which do not (Lager and Horte, 2002; Abd Rahman and Bennett, 2009; Abd Rahman et al., 2009). Collaboration may enable new equipment to be installed faster and at lower costs, and facilitates equipment optimization, troubleshooting and upgrading (Lager and Frishammar, 2010). Supplier resources that might facilitate the adoption process include instruction manuals, on-site training and temporary use of supplier operators (Farooq and O'Brien, 2010; Lager and Frishammar, 2010). Thus, the second research hypothesis was developed:

H2: The level of actual technology supplier (ATS) support realized is positively related to the level of manufacturing technology implementation performance (IP) success achieved.

Though technology implementation performance is important, a more critical issue from the adopting firm's perspective is if AMT installation performance impacts actual technology or operational performance (Efstathiades et al., 2002; Small, 2007). Companies that have collaborative relationships with their equipment supplier may realize higher levels of implementation success and higher levels of technology performance as well (Udo and Ehie, 1996; Lager and Horte, 2002; Abd Rahman et al., 2009). Poor installation performance may lead to poor technology performance. In process industries for example, prolonged installation and startup efforts may decrease operational profits, destroy a project, or in extreme cases devastate the firm (Lager and Frishammar, 2010). Thus, the third research hypothesis was developed.

H3: The level of manufacturing technology implementation performance (IP) success achieved is positively related to the level of manufacturing technology performance (TP) success achieved.

Manufacturing technology may enable firms to compete in dynamic environments by simultaneously providing high levels of performance on multiple competitive dimensions (Zhang et al., 2006). Within a manufacturing context, such 
competitive dimensions and objectives might include quality, cost and cycle time for example (Brown, 2001). Though the most direct measure of a technology's effectiveness may be its ability to improve manufacturing performance rather than a firm's competitive performance (Small, 2007), ultimately the objective of the firm is to realize competitive performance benefits. AMT performance outcomes may relate to business outcomes such as market growth and profitability for example (Kotha and Swamidass, 2000; Raymond and Croteau, 2009). Thus, the fourth hypothesis is developed.

H4: The level of manufacturing technology performance (TP) success achieved is positively related to the level of business performance (BP) achieved.

The literature review and the four hypotheses lead to the development of the research model (Figure 1). The model suggests that adopting firms which proactively consider supplier support as a key resource facilitating condition (NTS) are likely to receive such support (ATS), that ATS facilitates successful implementation performance (IP), which in turn is positively related to technology performance (TP) which should support business performance (BP).

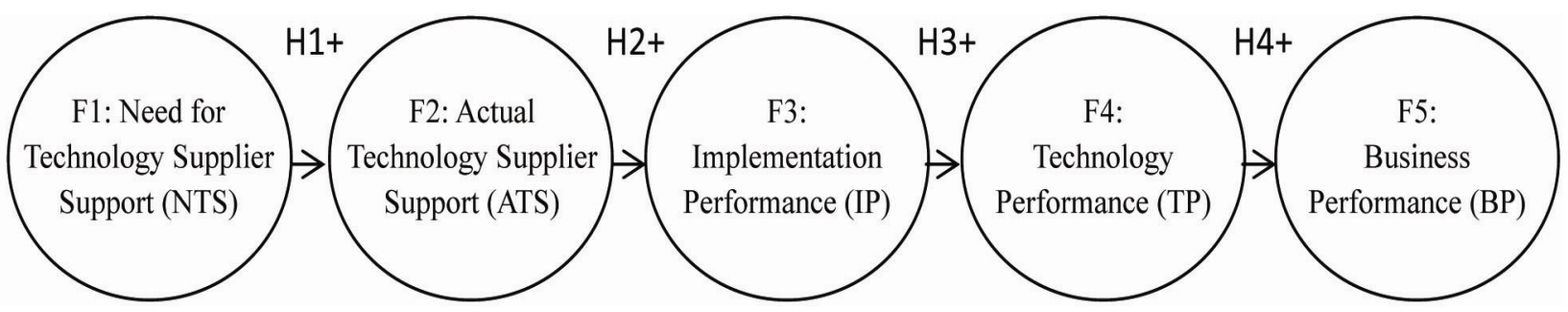

Figure 1. Supplier Support Technology Adoption Model

\section{Research methodology}

Prior studies of SFMT adoption consist largely of case studies, though notable large scale empirical studies are cited herein. Case studies are very useful for building theories and getting to the heart of relationships (Eisenhardt 1989); however, the results of case studies are often difficult to generalize (Kerlinger 1986). Large-scale empirical testing is useful because standardized measures can be used across a broad population in order to make generalizable conclusions (Fowler 1988). A survey was used in this research to empirically test hypotheses associated with SFMT adoption. Empirical research in this direction will be required if SFMT adoption is to be transformed into a formally evaluated discipline.

Using a structured survey, companies evaluated a recently implemented (within the prior year) SFMT. A preliminary version of the survey was drafted based on the literature and discussions with industry experts and researchers. Interviews were then conducted with four companies and the instrument was pretested. Most questions were eleven point Likert scaled (0 to 10). Manufacturing firms in the United States classified under the following North American Industry Classification System (NAICS) codes formed the target population: 332XXX (Fabricated Metal Products), 333XXX (Industrial Machinery and Equipment), 335XXX (Electronic and Other Electrical Equipment) and 337XXX (Transportation Equipment).

A three step process to collecting data was used (Dillman, 1978). The survey was sent to 2,370 managers. After two weeks, non-respondents were sent a reminder. This effort resulted in 52 responses. A second mailing provided 71 more responses (123 total responses). The effective sample size was 2,030 after adjusting for undeliverable surveys and ineligible participants (De Vaus, 2002). Statistical conclusion validity would have been a potential problem if the power were not high enough. Cook and Campbell (1979) note that when the sample size is small it is dangerous to rely solely on statistical significance. However, with just over 2,300 managers being targeted, and only around thirty parameters in the model being estimated, a $5-10 \%$ response rate would provide the statistical power required. This study has a sample size large enough to provide that statistical power.

Early to late respondent survey comparisons were made to analyze potential non-response bias (Armstrong and Overton, 1977). The means of 10 randomly selected questions were compared between the first $25 \%$ of responses and the last $25 \%$ of responses. No statistically significant differences were found between responses. Also, the NAICS code distribution for the original sample and for the respondents resulted in an approximately equal distribution. These outcomes suggest that concerns of non-response bias are mitigated to some extent.

The difficulty of achieving a higher response rate was expected because new SFMT investments are made infrequently, in part due to the long useful life of the technology. Respondents indicated that the expected life of their SFMT without requiring major re-tooling or re-investment was 8.25 years. Also, phone interviews with 70 non-respondents indicated that $32 \%$ of the managers did not participate because they did not recently invest in an SFMT. 


\section{Data Analysis}

\subsection{Respondent Profiles}

Table 1 presents the NAICS codes of responding firms. The total exceeds 123 because some respondents reported more than one code. The average annual sales for respondents was $\$ 231$ million $(n=83)$.

Table 1. Respondent Industry Codes

\begin{tabular}{llc}
\hline NAICS & Approximate Description & Frequency \\
\hline $332 X X X$ & Fabricated Metal Products & 33 \\
$333 X X X$ & Industrial Machinery and Equipment & 37 \\
$335 X X X$ & Electronic and Other Electrical Equipment & 40 \\
$336 X X X$ & Transportation Equipment & 42 \\
\hline
\end{tabular}

Table 2 presents respondent titles. Miller and Roth (1994) suggest that greater attention to informant selection can help to overcome the common method variance problem when practical considerations require single respondents. Ideally, information should be gathered from multiple respondents at each site to minimize the potential for bias from a single respondent (Klassen and McLaughlin 1996). However, the cost and time associated with obtaining access to multiple individuals at each site was beyond those available for this study. Such a strategy was not adopted because the response rate would likely be depressed to a critical level. Therefore, only single respondents were targeted. The pretest revealed that directors or managers in operations, capital equipment planning or manufacturing engineering would be qualified to answer the questions objectively.

Table 2. Respondent Titles

\begin{tabular}{ll}
\hline Title & Frequency \\
\hline Director or Manager of Manufacturing/Operations & 58 \\
Director or Manager of Capital Equipment Planning/Procurement & 31 \\
Director or Manager of Manufacturing Engineering & 19 \\
Vice President of Manufacturing/Operations & 9 \\
President, Vice President or General Manager & 5 \\
Director of Finance/Corporate Strategic Technology Management & 1 \\
Director of Quality Assurance & 1 \\
\hline
\end{tabular}

Table 3 lists the manufacturing technology adopted. The research required that participants adopted an SFMT within the last year. Some technologies (e.g., a robotic laser welder) could have been classified in multiple categories. The average cost of the SFMT was approximately $\$ 986,000(\mathrm{n}=119)$. The average time from installation to process optimization was 6.5 months $(\mathrm{n}=105)$.

Table 3. SFMT Adopted

\begin{tabular}{ll}
\cline { 2 - 2 } Title & Frequency \\
\cline { 2 - 3 } CNC/DNC & 79 \\
Robotics & 33 \\
Material working laser & 12 \\
\cline { 2 - 2 }
\end{tabular}

Descriptive statistics, loadings and $t$-values for the manifest variables are provided in Table 4. Confirmatory Factor Analysis (CFA) and Structural Equation Modeling (SEM) were employed to test the theoretical framework. The data were analyzed with confirmatory factor analysis (CFA) as opposed to exploratory factor analysis (EFA). A CFA is based on statistical tests in which all the key psychometric properties can be assessed. Therefore, a CFA seemed better suited for a paper where a major contribution is the development of scales (Mulaik, 1972; Bentler, 1992). The CFA approach is most often used to test instrument validation and modify instruments for better psychometric properties (Anderson and Gerbing, 1988; Bollen, 1989; Venkatraman, 1989; Byrne, 1988). The following minimal subset was considered important for assessing the measurement properties of a construct: unidimensionality and convergent validity, discriminant validity, criterion-related validity, nomological validity, and reliability.

The reason for using SEM was two-fold: 1) it provided a straightforward method of dealing with multiple relationships simultaneously while providing statistical efficiency; and 2) its ability to assess the relationships comprehensively 
provided a transition from exploratory to confirmatory analysis. This transition will hopefully correspond to a greater effort in the SFMT adoption field toward developing a more systematic and holistic view. However, such efforts will require the ability to test a series of relationships constituting a large-scale model. This is a task for which SEM is well-suited. Moreover, SEM allows for a statistical test of the goodness-of-fit for the proposed confirmatory factor solution, which is not possible with principal components/factor analysis.

EQS 6.1 was used to test the confirmatory factor model and the structural equation model (Bentler, 1995). Model fit was assessed using three indices: the Bentler Bonnet Non-Normed Fit Index (BBNNFI), the comparative fit index (CFI) and the root-mean-square error of approximation (RMSEA). Discussion of these indices may be found in Gerbing and Anderson (Gerbing and Anderson, 1992), Hu and Bentler (Hu and Bentler, 1999), and Marsh, Balla and Hau (1996). Satisfactory model fit is indicated by RMSEA values less than or equal to .08, and CFI, BBNNFI values greater than or equal to .90 .

Confirmatory Factor Analysis (CFA) was used to validate the measurement model. This measurement model was tested using EQS with maximum likelihood estimation (Jöreskog and Sörbom, 1982). The estimation of parameters in the model was determined using maximum likelihood (ML) estimation (Bentler, 1989, 1992; Bollen, 1989; Joreskog and Sorbom, 1993). The applications were executed using the EQS/Windows program. According to Anderson and Gerbing (1988), a fundamental distinction can be made between the use of structural equation modeling (SEM) for theory testing and development versus predictive application. For clarity, they characterize this choice as one between a full-information (ML) estimation approach and a partial least squares (PLS) estimation approach. These two approaches to SEM can be thought of as a complementary choice that depends on the purpose of the research: 1) ML for theory testing and development (this study) and PLS for application and prediction. Drawing on this distinction, a confirmatory approach to theory testing and development using ML methods was used.

More practical indices of fit include the RMSEA, Bentler-Bonett non-normed (BBNNFI) fit indices (Bentler and Bonett 1980), and the comparative fit index (CFI) (Bentler, 1990), a revised version of the NFI that overcomes the underestimation of fit in small sample sizes (i.e., given a correct model and small sample, the NFI may not reach 1; Bentler 1992). Although these three indices of fit are provided in the EQS output, Bentler (1992) recommends the BBNFI and CFI to be the indices of choice. Each provides a measure of complete covariation in the data, with a value greater than 0.90 indicating an acceptable fit to the data. The fit indices for the confirmatory model indicate an acceptable fit to the data: $[\mathrm{CFI}=.93 ; \mathrm{BBNNFI}=.91 ; \mathrm{RMSEA}=.076]$. All factor loadings were of sufficient magnitude and significantly different from zero at the $\mathrm{p}=.05$ level.

The convergent validity of the scales (the extent to which the measured items reflect a common underlying construct) was supported, with estimated coefficients of all indicators being significant $(t>2.0)$. The average variance extracted (AVE), which measures the variance captured by the indicators relative to measurement error, was also at least the 0.50 minimum necessary to justify the use of a construct (Hair et al., 1998). Composite reliability values also provide a further assessment of internal consistency. A minimum value of 0.70 is recommended as it indicates that approximately $50 \%$ of the variance (the squared loading) can be attributed to the construct of interest (Fornell and Larcker, 1981). The composite reliabilities ranged from .72 to .85 . All tests of discriminant validity were supportive. That is, no confidence intervals of the correlations for the constructs ( $\phi$ values) included $1.0(p<.05)$ (Anderson and Gerbing, 1988), and the square of the intercorrelations between two constructs, $\phi^{2}$, was less than the AVE estimates of the two constructs. This was true for all pairs of constructs (Fornell and Larcker, 1981). There were no examples of parameters exhibiting unreasonable estimates (e.g., correlations greater than 1.0, negative variances). Furthermore, the sign and significance of the item loadings, along with an assessment of reliability indices for each factor using Cronbach's alpha support the satisfactory fit of the model to the data. These results suggest the five latent variables and their 14 manifest variables are reliable and valid. The inter-item correlations, Cronbach's alpha, composite reliabilities (CR), and average variance extracted (AVE) values are shown in Table 5.

The structural model was tested, with maximum likelihood (ML) estimation, and the covariance matrix used as input to the model. The model was recursive and identified. The fit indices for the structural model indicate an acceptable fit to the data: $[\mathrm{CFI}=.926 ; \mathrm{BBNNFI}=.907$; RMSEA $=.076]$. The structural model explained $14 \%$ of the variation in actual technology supplier support, $6.5 \%$ in implementation performance, $29.4 \%$ in technology performance and $48.3 \%$ in business performance. The results are presented in Figure 2, and demonstrate that all four proposed hypotheses were supported.

The four hypothesized relationships were found to be related in the theoretically predicted manner. The proactive consideration of the need for technology supplier support was found to have a significant positive effect on the level of actual support realized ( $\beta=0.379, p<0.5$ ), supporting H1. The level of actual supplier support realized was found to 
have a significant positive effect on the level of manufacturing technology implementation performance (IP) success achieved $(\beta=0.255, p<.05)$, supporting $\mathrm{H} 2$. The level of manufacturing technology implementation performance (IP) success achieved was found to have a significant positive effect on the level of manufacturing technology performance (TP) success achieved ( $\beta=0.542, p<0.05)$, supporting H3. The level of manufacturing technology performance (TP) success achieved was found to have a significant positive effect on the level of business performance (BP) achieved ( $\beta$ $=0.695, p<0.05)$, supporting H4. Table 4. Manifest Variables - Loadings, t-values, Descriptive Statistics

\begin{tabular}{lcccc}
\hline Factors and Items & $\begin{array}{c}\text { Standardized } \\
\text { loading }\end{array}$ & $\begin{array}{c}\text { Error } \\
\text { term }\end{array}$ & $t$-value & $\begin{array}{c}\text { Mean and } \\
\text { (std dev.) }\end{array}$ \\
\hline
\end{tabular}

Need for Technology Supplier Support (NTS) - People involved in the decision to make the item internally (insource) believed that successful insourcing would require us to select an:

NTS1: AMT supplier that provided significant AMT installation support

$\begin{array}{cccc}.820 & - & - & 7.49 \\ & & & (1.98) \\ .818 & .576 & 8.64 & \begin{array}{c}7.34 \\ (2.05)\end{array} \\ .776 & .631 & 8.68 & (1.78)\end{array}$

NTS2: AMT supplier that provided extensive training for our personnel

NTS3: AMT supplier that provided installation, operation and maintenance manuals

the agreement with the following statements. The

Actual Technology Supplier Support (ATS) - Please rate extent of agreement with the following statements. The AMT supplier provided:

ATS1: Valuable inputs to improve product design/manufacturability

$\begin{array}{cccc}.650 & - & - & 4.74 \\ & & & (2.80) \\ .912 & .410 & 6.89 & (2.24) \\ & & & 6.51 \\ .739 & .674 & 6.71 & (2.17)\end{array}$

ATS3: Significant AMT installation support

ATS2: Technology improvements in the AMT specific to our needs

optimization performance results relative to Implementation Performance
goals for each measure below:

\begin{tabular}{|c|c|c|c|}
\hline IP1: Budget required to optimize process & .567 & - & - \\
\hline $\begin{array}{c}\text { IP2: Number or complexity of AMT technical } \\
\text { installation / optimization problems }\end{array}$ & .878 & .478 & 5.24 \\
\hline $\begin{array}{l}\text { IP3: Disruption to ongoing production operations during } \\
\text { installation / optimization }\end{array}$ & .624 & .782 & 5.03 \\
\hline
\end{tabular}

Technology Performance (TP) - For the first 6 months of production after process optimization, please rate average production performance relative to goals for:
TP1: Defect rate
.858
$.514 \quad 5.84$
5.78
$(2.10)$
TP2: Overall production cycle times
.627

Business Performance (BP) - For the first 6 months of production after process optimization, please rate the average contribution of ITEMS made on the AMT to:

BP1: Profit on the sale of the item or end product the item is installed in

BP2: Sales volume of the item or end product the item is installed in

BP3: Customer satisfaction with the item or end product the item is installed in

$\begin{array}{cccc}.856 & .517 & 9.81 & 5.80 \\ & & & (1.71) \\ .837 & - & - & 5.82 \\ & & & (1.84) \\ .721 & .693 & 8.26 & (1.82)\end{array}$

Note: NTS and ATS scales were $0=$ strongly disagree, $10=$ strongly agree: IP, TP and BP were $0=$ far worse than goals, $10=$ much better than goals. 
Table 5. Correlation Matrix and Descriptive Statistics

\begin{tabular}{lccccc}
\hline Variable $^{\mathrm{a}}$ & NTS & ATS & IP & TP & BP \\
\hline NTS & $\mathbf{0 . 8 4 6}$ & & & & \\
ATS & 0.370 & $\mathbf{0 . 7 9 0}$ & & & \\
IP & 0.131 & 0.250 & $\mathbf{0 . 7 1 9}$ & & \\
TP & 0.082 & 0.016 & 0.548 & $\mathbf{0 . 7 0 0}$ & \\
BP & 0.114 & 0.268 & 0.359 & 0.692 & $\mathbf{0 . 8 4 7}$ \\
Mean & 7.473 & 5.779 & 5.345 & 5.878 & 5.978 \\
Standard Deviation & 1.943 & 2.415 & 1.898 & 1.990 & 1.796 \\
Composite Reliability & 0.850 & 0.820 & 0.740 & 0.720 & 0.850 \\
Average Variance Extracted & 0.650 & 0.600 & 0.500 & 0.560 & 0.650 \\
& & & & & \\
\hline
\end{tabular}

${ }^{a}$ Cronbach's alpha shown on the diagonal
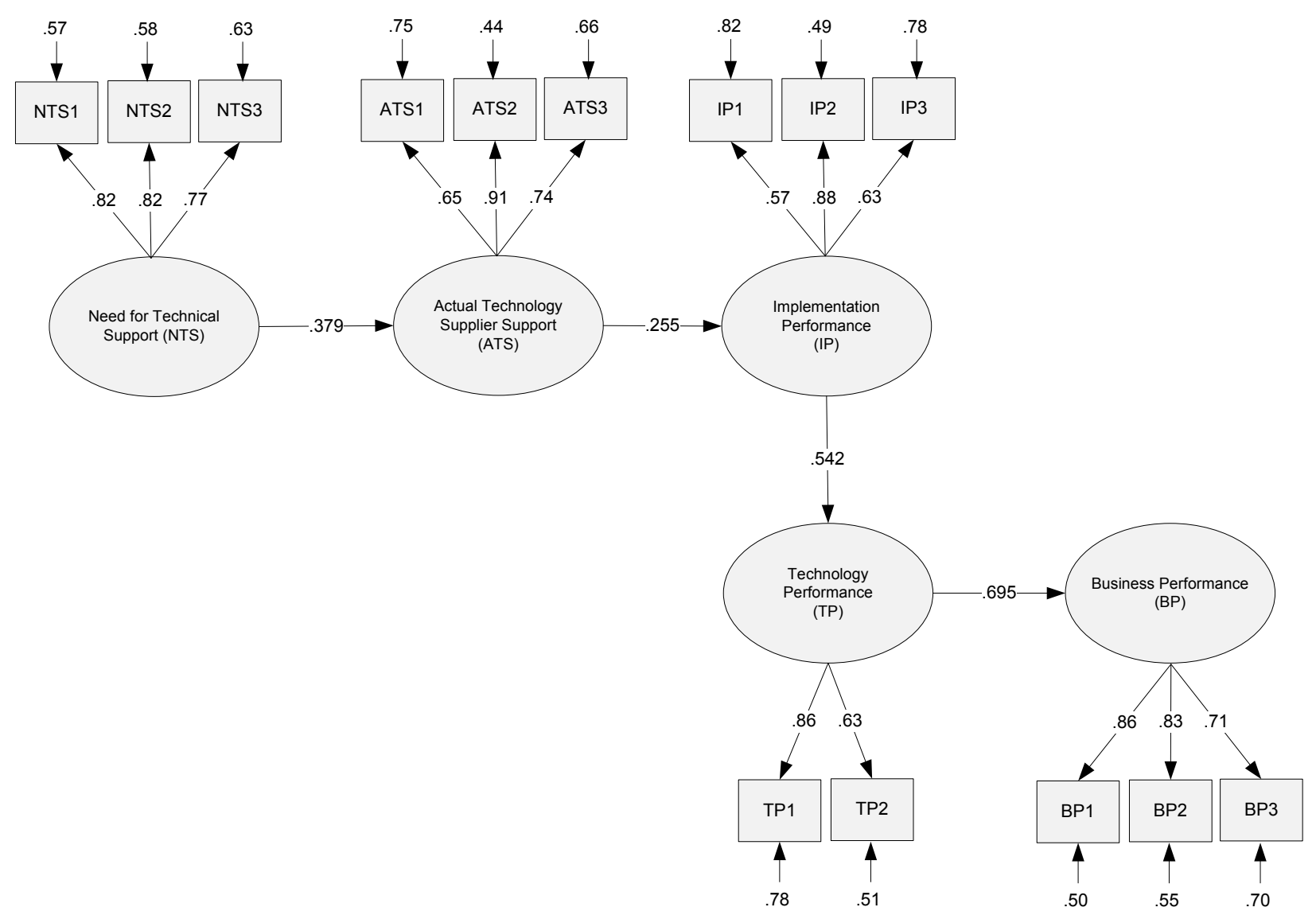

Figure 2. Structural Model

\section{Discussion}

\subsection{Managerial implications}

Investment in SFMT represents a considerable commitment of financial and organizational resources. This commitment is an important strategic decision designed to improve competitive position and generate economic performance improvements. This research found that supplier collaboration influences the success of SFMT adoption and subsequently performance of a firm. Given our understanding of the importance of tacit knowledge to successful 
transfer of technology, perhaps success in the transfer of SFMT is enhanced with increased inclusion of the tacit attributes of the technology through hands-on collaboration between AMT supplier and buyer.

Supplier participation in AMT implementation increases the possibility that AMT adopters will realize the strategic advantage they envision when pursuing AMT. Adopters of technology, particularly those that compete on time to market for example, should evaluate not only their internal infrastructure to determine its ability to adopt new technologies but external resource facilitating factors such as technology supplier support as well. This suggests that prior to making a technology investment, adopting firms may want to enhance their technology supplier evaluation processes to include dimensions now commonly found in direct material and component supplier assessment criteria. Such factors might include AMT supplier willingness to collaborate, cultural alignment, communication and team skills, trust, supplier knowledge of materials processing, prior training and support experiences with the supplier, and supplier field service effectiveness for example. Research indicates that adopting companies will conduct extensive evaluations of the technology itself, but it is not clear if AMT supplier support capabilities are proactively evaluated by adopting firms. AMT suppliers that have excellent installation support services may develop a competitive advantage through such services and should market the benefits of such services to potential adopters. The technology itself may become more of an order qualifier, while attributes such as service support, responsiveness and collaboration capabilities increasingly become order winners.

\subsection{Limitations}

This research advances the literature stream investigating the performance implications of AMT adoption. The research should inform researchers and practitioners interested in AMT adoption and motivate both groups to increase the consideration of AMT supplier support during technology selection and implementation. However, the following limitations should be noted.

The extension of the findings across broader AMT types and contexts is limited by the design of the study because only specific technologies were considered. However, the focus on a specific category of AMT provided the benefit of accurate targeting of informed respondents and mitigated potential definitional and contextual problems.

A relatively low response rate was expected because all respondents were required to have invested in a specific AMT within the last year. The potential impact of non-response bias was addressed by using multiple efforts to increase response rate, phone interviews with non-respondents, and statistical tests that compared early to late respondents. Future research might consider screening targeted respondents to ensure they are viable respondents, as has been done in some prior studies (Abd Rahman et al., 2009). This may lead to a higher response rate but requires substantial resources without which may significantly limit sample size, so trade-offs in methodology need to be considered (Lewis and Boyer, 2002).

Self-assessment measures and a single respondent were used, as is often the case with large-scale survey research. These commonly used approaches in empirical research raise questions about halo effects and bias for example. Pre-testing the instrument with multiple informants, using follow up case studies and interviews, and targeting the most informed respondent helped mitigate such concerns.

\subsection{Future research directions}

H1 was supported (NTS is positively related to ATS). Future research might investigate which qualitative or service criteria are most predictive of AMT supplier support capabilities. Investigation of how potential moderating factors such as technology newness or organizational readiness might impact the need for supplier support is also suggested. For example, technology newness may impact the level of transfer required and the duration of the collaboration contract (Lager and Frishammar, 2010). Prior research suggested that uncertainty and asset specificity impacted the strength of buyer and supplier relationships, though level of complexity had no such impact (Abd Rahman et al., 2009).

H2 was supported (ATS is positively related to IP success). This research focused on the potential benefits of AMT buyer/supplier collaboration during the implementation stage of the technology transfer process. Future research might investigate the potential needs and critical success factors for equipment supplier and adopter collaboration during different phases of the equipment lifecycle. Different types and levels of resource commitment, relationship intensity and performance outcomes may be identified during the development, purchasing, start-up and production phases of the equipment lifecycle (Lager and Frishammar, 2010). Also, future research might investigate how other facilitating factors besides supplier support might impact adoption success, including for example supporting technology systems, project management skills and technological compatibility.

H3 was supported (IP success is positively related TP). Though research suggests that this relationship exists, there are few studies that empirically test it. Future research might explore which specific implementation performance 
dimensions are most critical to subsequent technology performance. Perhaps technology justification methods (e.g., payback period and return on investment analysis) will need to be modified to incorporate the upgrading (or degrading) of operational and business performance expectations based on implementation risks, supplier support and expected outcomes.

$\mathrm{H} 4$ was supported (TP success is positively related BP success). It is recognized that business performance outcomes are influenced by many factors besides technology performance (Small, 2007). Other drivers of business performance may include financial strength, market reach, strategic focus and competitive reaction for example. Future research may consider the moderating effect of manufacturing and business strategy alignment on business performance outcomes.

Future research directions not directly linked to the hypotheses might also be pursued. For example, this research focused on the motivations of adopting (buying) firms to collaborate with manufacturing technology suppliers. Future research may want to examine the effects of a supplying firm's motivations on the development and outcomes of such collaborative relationships. Without an appropriate balance of risk and rewards, the technology supplier may be less willing to provide the support sought by the adopting firm. A supplying firm may expect to gain new knowledge, create barriers to competition, and gain access to new markets for example (Small and Yasin, 1997).

\section{References}

Abd Rahman, A. \& Bennett, D. (2009). Advanced Manufacturing Technology Adoption in Developing Countries: The Role of Buyer-Supplier Relationships, Journal of Manufacturing Technology Management, Vol. 20, No. 8, pp. 1099-1118. http://dx.doi.org/10.1108/17410380910997236

Abd Rahman, A., Brookes, N. \& Bennett, D. (2009). The Precursors and Impacts of BSR on AMT Acquisition and Implementation, IEEE Transactions on Engineering Management, Vol. 56, No. 2, pp. 285-297. http://dx.doi.org/10.1109/TEM.2009.2016070

Anderson, J. C. \& Gerbing, D. W. (1988). Structural Equation Modeling in Practice: A Review and Recommended Two-Step Approach, Psychological Bulletin, Vol. 103, No. 3, pp. 411-423. http://dx.doi.org/10.1037/0033-2909.103.3.411

Armstrong, J. S. \& Overton, T. S. (1977). Estimating Nonresponse Bias in Mail Surveys, Journal of Marketing Research, Vol. 14, No. 3, pp. 396-402. http://dx.doi.org/10.2307/3150783

Baldwin, J. \& Lin, Z. (2002). Impediments to Advanced Technology Adoption for Canadian Manufacturers, Research Policy, Vol. 31, No. 1, pp. 1-18. http://dx.doi.org/10.1016/S0048-7333(01)00110-X

Bentler, P.M. (1989). EQS: Structural Equations Program Manual. Los Angeles: BMDP Statistical Software.

Bentler, P.M. (1990). Comparative fit indexes in structural models. Psychological Bulletin, 107, 238-246. http://dx.doi.org/10.1037/0033-2909.107.2.238

Bentler, P.M. (1992). EQS: Structural Equations Program Manual. Los Angeles: BMDP Statistical Software.

Bentler, P. (1995). EQS Structural Equations Program Manual, Multivariate Software, Inc., Encino, CA.

Bentler, P.M., \& Bonett, D.G. (1980). Significance tests and goodness of fit in the analysis of covariance structures. Psychological Bulletin, 88, 588-606. http://dx.doi.org/10.1037/0033-2909.88.3.588

Bollen, K.A. (1989). Structural Equations with Latent Variables. New York: John Wiley.

Boyer, K., Leong, G., Ward, P. \& Krajewski, L. (1997). Unlocking the Potential of Advanced Manufacturing Technologies, Journal of Operations Management, Vol. 15, No. 4, pp. 331-347. http://dx.doi.org/10.1016/S0272-6963(97)00009-0

Boyle, T. A. (2006). Towards Best Management Practices for Implementing Manufacturing Flexibility, Journal of Manufacturing Technology Management, Vol. 17, $\quad$ No. 1, pp. 6-21. http://dx.doi.org/10.1108/17410380610639470

Brown, S. R. (2001). Managing Process Technology: Further Empirical Evidence from Manufacturing Plants, Technovation, Vol. 21, No. 8, pp. 467-478. http://dx.doi.org/10.1016/S0166-4972(00)00074-2

Byrne, B.M. (1988). The Self Description Questionnaire III: Testing for equivalent factorial validity across ability. Educational and Psychological Measurement, 48, 397-406. http://dx.doi.org/10.1177/0013164488482012

Cook T, Campbell D. (1979). Quasi-Experimentation - Design and Analysis Issues for Field Settings. Houghton-Miffl in: Boston, MA. 
Dangayach, G. S. \& Deshmukh, S. G. (2004). Advanced Manufacturing Technologies: Evidences from Indian Automobile Companies, International Journal of Manufacturing Technology \& Management, Vol. 6, No. 5, pp. 426-433. http://dx.doi.org/10.1504/IJMTM.2004.005671

De Vaus, D. A. (2002). Surveys in Social Research, Allen \& Unwin,

Dillman, D. (1978). Mail and Telephone Surveys: The Total Design Method, John Wiley and Sons, New York.

Efstathiades, A., Tassou, S. \& Antoniou, A. (2002). Strategic Planning, Transfer, and Implementation of Advanced Manufacturing Technologies (AMT): Development of an Integrated Process Plan, Technovation, Vol. 22, No. 4, pp. 201-212. http://dx.doi.org/10.1016/S0166-4972(01)00024-4

Eisenhardt, K.M. (1989). Building theories from case study research. Academy of Management Review, 14(4), 532-550.

Farooq, S. \& O'Brien, C. (2010). Risk Calculations in the Manufacturing Technology Selection Process, Journal of Manufacturing Technology Management, Vol. 21, $\quad$ No. 1, pp. 28-49. http://dx.doi.org/10.1108/17410381011011470

Fornell, C. \& Larcker, D. F. (1981). Evaluating structural equation models with unobservable variables and measurement error, Journal of Marketing Research, Vol. 18, No. 1, pp. 39-50. http://dx.doi.org/10.2307/3151312

Fowler, F.J., Jr. (1988). Survey Research Methods. Newbury Park: Sage Publications.

Gerbing, D. W. \& Anderson, J. C. (1992). Monte Carlo Evaluations of Goodness of Fit Indices for Structural Equation Models, Sociological Methods and Research, Vol. 21, No. 2, pp. 132-160. http://dx.doi.org/10.1177/0049124192021002002

Gouveia da Costa, S. E. \& Pinheiro de Lima, E. (2009). Advanced Manufacturing Technology Adoption: An Integrated Approach, Journal of Manufacturing Technology Management, Vol. 20, No. 1, pp. 74-96. http://dx.doi.org/10.1108/17410380910925415

Hair, J. F., Anderson, R. E., Tatham, R. L. \& Black, W. C. (1998). Multivariate Data Analysis, Prentice-Hall, Englewood Cliffs, NJ.

Hsiao, C. H. \& Yang, C. (2011). The Intellectual Development of the Technology Acceptance Model: A Co-Citation Analysis, International Journal of Information Management, Vol. 31, No. 2, pp. 128-136. http://dx.doi.org/10.1016/j.ijinfomgt.2010.07.003

Hu, L. \& Bentler, P. (1999). Cutoff Criteria for Fit Indices in Covariance Structure Analysis: Conventional Criteria Versus New Alternatives, Structural Equation Modeling: A Multidisciplinary Journal, Vol. 6, No. 1, pp. 1-55. http://dx.doi.org/10.1080/10705519909540118

Jöreskog, K. G. \& Sörbom, D. (1982). Systems under indirect observation, Part I and Part II, North-Holland, Amsterdam.

Joreskog, K.G., \& Sorbom, D. (1993). New Features in LISREL 8. Chicago: Scientific Software.

Kerlinger, F.N. (1986). Foundations of Behavioral Research (Third Edition). Fort Worth, TX: Harcourt Brace Jovanovich College Publishers.

King, W. R. \& He, J. (2006). A Meta-Analysis of the Technology Acceptance Model, Information \& Management, Vol. 43, No. 6, pp. 740-755. http://dx.doi.org/10.1016/j.im.2006.05.003

Klassen, R.D., \& McLaughlin, C.P. (1996). The impact of environmental management on firm performance. Management Science, 42(8), 1199-1214. http://dx.doi.org/10.1287/mnsc.42.8.1199

Kotha, S. \& Swamidass, P. M. (2000). Strategy, Advanced Manufacturing Technology and Performance: Empirical Evidence from U.S. Manufacturing Firms, Journal of Operations Management, Vol. 18, No. 3, pp. 257-277. http://dx.doi.org/10.1016/S0272-6963(99)00025-X

Lager, T. \& Frishammar, J. (2010). Equipment Supplier/User Collaboration in the Process Industries: In search of Enhanced Operating Performance, Journal of Manufacturing Technology Management, Vol. 21, No. 6, pp. 698-720. http://dx.doi.org/10.1108/17410381011064003

Lager, T. \& Horte, S. A. (2002). Success Factors for Improvement and Innovation of Process Technology In Process Industry, Integrated Manufacturing Systems, Vol. 13, No. 3, pp. 158-164. http://dx.doi.org/10.1108/09576060210416607 
Lewis, M. \& Boyer, K. (2002). Factors Impacting AMT Implementation: An Integrative and Controlled Study, Journal of Engineering and Technology Management, Vol. 19, No. 2, pp. 111-130. http://dx.doi.org/10.1016/S0923-4748(02)00005-X

Marsh, H. W., Balla, J. R. \& Hau, K.-T. (1996). An evaluation of incremental fit indices: a clarification of mathematical and empirical properties. Advanced Structural Equation Modeling: Issues and Techniques. G. Marcoulides \& R. Schumacker. Mahwah, NJ, Lawrence Erlbaum Associates: 315-345.

Miller, J.G., \& Roth, A.V. (1994). A taxonomy of manufacturing strategies. Management Science, 40(3), March, 285-304. http://dx.doi.org/10.1287/mnsc.40.3.285

Mital, A. \& Pennathur, A. (2002). Getting the Most out of Advanced Manufacturing Technology (AMT)-based Systems: Part I: Recognizing and Managing Technology Limitations, International Journal of Technology and Management, Vol. 4, No. 1/2, pp. 96-118.

Monge, C. A. M., Rao, S. S., Gonzalez, M. E. \& Sohal, A. S. (2006). Performance Measurement of AMT: A Cross-Regional Study, Benchmarking An International Journal, Vol. 13, No. 1/2, pp. 135-146.

Mulaik, S.A. (1972). The Foundations of Factor Analysis. McGraw-Hill, New York.

Percival, J. (2009). Complementarities Between Advanced Manufacturing Technologies, IEEE Transactions on Engineering Management, Vol. 56, No. 1, pp. 115-128. http://dx.doi.org/10.1109/TEM.2008.927784

Raymond, L. \& Croteau, A. M. (2009). Manufacturing Strategy and Business Strategy in Medium-Sized Enterprises: Performance Effects of Strategic Alignment, IEEE Transactions on Engineering Management, Vol. 56, No. 2, pp. 192-202. http://dx.doi.org/10.1109/TEM.2008.922646

Scannell, T., Calantone, R. \& Melnyk, S. (2012). Shop Floor Manufacturing Technology Adoption Decisions: An Application of the Theory of Planned Behavior, Journal of Manufacturing Technology Management, Vol. 23, No. 4, pp. 464-483. http://dx.doi.org/10.1108/17410381211230420

Scannell, T., Melnyk, S. \& Calantone, R. (2011). Shop Floor Manufacturing Technology Adoption: An Adaptation of the Technology Acceptance Model, International Journal of Manufacturing Technology and Management, Vol. 23, No. 3/4, pp. 193-213. http://dx.doi.org/10.1504/IJMTM.2011.045516

Schepers, J. \& Wetzels, M. (2007). A Meta-Analysis of the Technology Acceptance Model: Investigating Subjective Norm and Moderation Effects, Information \& Management, Vol. 44, No. 1, pp. 90-103. http://dx.doi.org/10.1016/j.im.2006.10.007

Small, M. H. (2007). Planning, Justifying and Installing Advanced Manufacturing Technology: A Managerial Framework, Journal of Manufacturing Technology Management, Vol. 18, No. 5, pp. 513-537. http://dx.doi.org/10.1108/17410380710752635

Small, M. H. \& Chen, I. J. (1995). Investment Justification of Advanced Manufacturing Technology: An Empirical Analysis, Journal of Engineering and Technology Management, Vol. 12, No. 1/2, pp. 27-55. http://dx.doi.org/10.1016/0923-4748(95)00003-5

Small, M. H. \& Yasin, M. M. (1997). Advanced Manufacturing Technology: Implementation Policy and Performance, Journal of Operations Management, Vol. 15, No. 4, pp. 349-370. http://dx.doi.org/10.1016/S0272-6963(97)00013-2

Stock, G. \& Tatikonda, M. (2000). A Typology of Project-Level Technology Transfer Processes, Journal of Operations Management, Vol. 18, No. 6, pp. 719-737. http://dx.doi.org/10.1016/S0272-6963(00)00045-0

Udo, G. J. \& Ehie, I. C. (1996). Critical Success Factors for Advanced Manufacturing Systems, Computers \& Industrial Engineering, Vol. 31, No. 1/2, pp. 91-94. http://dx.doi.org/10.1016/0360-8352(96)00086-1

Venkatraman, N. (1989). Strategic orientation of business enterprises: The construct, dimensionality, and measurement. Management Science, 35(8), 942-962. http://dx.doi.org/10.1287/mnsc.35.8.942

Zhang, Q., Vonderembse, M. A. \& Cao, M. (2006). Achieving Flexible Manufacturing Competence: The Roles of Advanced Manufacturing Technology and Operations Improvement Practices, International Journal of Operations \& Production Management, Vol. 26, No. 6, pp. 580-599. http://dx.doi.org/10.1108/01443570610666957 